\title{
PROCESSOS DE CONSTITUIÇÃO IDENTITÁRIA DOS CHEFES DE DEPARTAMENTO DOS CURSOS DE LICENCIATURA
}

\author{
Processes of identity constitution among \\ department leaders in licentiate courses
}

\author{
Márcia Hobold ${ }^{a}$, Marli Eliza Dalmazo Afonso de Andréb \\ ${ }^{a}$ Doutoranda em Educação - Psicologia da Educação da PUC-SP, \\ São Paulo, SP - Brasil, e-mail: gmhobold@terra.com.br \\ b Professora do Programa de Educação: Psicologia da Educação da PUC SP, \\ São Paulo, SP - Brasil, e-mail: marliandre@pucsp br
}

\begin{abstract}
Resumo
O presente texto focaliza os processos de constituição identitária dos chefes de departamento dos cursos de licenciatura de uma universidade privada do sul do país. Os procedimentos de coleta de dados incluem análise de documentos da instituição, entrevistas com os chefes dos nove cursos de licenciatura, com gestores da universidade e com professores formadores. Para fins do presente texto, serão discutidos os dados de entrevistas realizadas com os chefes de departamento. Constatou-se que a função de chefe de departamento requer algumas competências que vão muito além das necessárias ao exercício da docência. Assim, involuntariamente, há um "choque de realidade" diante de tantos afazeres diferentes, tais como: acompanhamento do orçamento, planejamento estratégico, co-responsabilidade pelas campanhas de marketing e pelo fechamento das matrículas dos estudantes. Algumas são relativamente novas, próprias ao contexto das universidades privadas, objetivando maximizar os resultados e reduzir custos, uma exigência dos tempos neoliberais. Entende-se, neste caso, que o trabalho realizado pelos
\end{abstract}

Rev. Diálogo Educ., Curitiba, v. 8, n. 23, p. 137-151, jan./abr. 2008 
professores, quando assumem a função de chefe de departamento, não está desvinculado das mudanças ocorridas no contexto sócio, político e econômico. O referencial teórico da pesquisa apóia-se em escritos de André (2006), Pérez Gómez (2001), Dubar (2005), Imbernón (2004) e Dias-da-Silva (2005). Os relatos dos chefes de departamento dos cursos de licenciatura sobre seu cotidiano de trabalho e sua trajetória revelaram dificuldades, prazeres e angústias no exercício desta função e possibilitaram compreender influências familiares, escolares e laborais na constituição de sua identidade profissional.

Palavras-chave: Identidade profissional; Licenciatura; Contexto universitário.

\begin{abstract}
The main objective of this paper is to analyze the processes of identity constitution of teacher education department heads of a private university in the South of the country. Data collection procedures include institutional document analysis, interviews with all nine department heads, with university deans and with teacher educators. As far as this paper is concerned only interviews data with the department heads will be discussed. It was found that acting as a department head requires some competences that go beyond those required to be a teacher. Therefore, unwontedly, there is a reality shock in face of the many diverse tasks they have to perform, such as budget monitoring, strategic and marketing planning and students' registration control. Some of those tasks are new and characteristic of private educational institutions, aiming at reinforcing outcomes and reducing costs, signs of globalized times. It is our understanding that the work that teachers perform while acting as department heads is not untied from the social, economic and political context. The research theoretical framework is based on writings of André (2006), Dubar (2005), Imbernón (2004) and Dias da Silva (2005). What the department heads report about their daily work and their life history reveal difficulties, pleasures, and anxiety to perform their tasks and made it possibly to understand family, schooling and job influences in their professional identity constitution processes.
\end{abstract}

Keywords: Professional identity; Teacher education course; University context. 
Processos de constituição identitária dos chefes de departamento dos cursos de licenciatura

Pesquisas realizadas sobre a formação dos professores têm fornecido pistas para pensar e/ou repensar as condições de trabalho dos professores formadores, as políticas públicas para esta modalidade de ensino e, também, para entender os direcionamentos do modelo neoliberal que, na maioria das vezes e de forma oculta, têm sido instaurados na gestão das universidades brasileiras.

As reformas impostas pelos organismos internacionais ao sistema empresarial estão sendo incorporadas, cada vez mais, pela administração universitária, principalmente nas universidades privadas. Assim, as formas de trabalho têm se modificado nas últimas décadas, modificando as identidades profissionais dos professores. Visto sob este aspecto, há uma relação de interdependência entre sujeito e instituição e vice-versa. As mudanças estruturais, decorrentes das transformações sociais, afetam diretamente a relação professor-universidade.

Com interesse específico nos processos de formação de professores, pretende-se conhecer de perto os cursos que vêm formando professores e mais especificamente o trabalho cotidiano dos gestores desses cursos - os coordenadores ou os chefes de departamento das licenciaturas. Entender como esses chefes realizam o seu trabalho no cotidiano universitário e qual a relação entre sua pessoa e a função que exercem possibilitará aumentar o conhecimento sobre os cursos de licenciatura e sobre a formação inicial de professores.

\section{Fundamentos do estudo}

A partir da década de 1990 cresceram muito as discussões e estudos sobre a formação de professores. Se ao longo dos anos 90 a média dos estudos e pesquisas sobre formação de professores girava em torno de $6 \%$, nos anos 2000 esse percentual mais do que dobrou. Das 2104 dissertações e teses defendidas na área de educação em 2003, 17\% tinham como tema central a formação de professores (ANDRÉ et al., 2006). Num período de dez anos, houve ainda uma grande mudança nas temáticas dos estudos: se nos anos $90 \mathrm{o}$ maior interesse se concentrava na formação inicial (72\%), nos anos 2000 são apenas $22 \%$ das pesquisas que abordam esse tema. Considera-se fundamental continuar as investigações sobre os cursos de formação inicial, daí a proposição do presente estudo.

Imbernón (2004) ressalta o valor da formação inicial na profissionalização docente. Acredita que é na formação inicial que ocorre a aprendizagem de virtudes, valores e do vínculo entre o saber intelectual e a realidade social, ou seja, da responsabilidade social. Segundo o autor, é também o momento em que ocorre a aprendizagem dos vícios, das rotinas, da desvalorização e das práticas não condizentes com os discursos.

Rev. Diálogo Educ., Curitiba, v. 8, n. 23, p. 137-151, jan./abr. 2008 
Para Imbernón (2004), é a formação inicial dos professores que deve proporcionar a aprendizagem de conhecimentos científicos, culturais, contextuais, psicopedagógicos e pessoais que acompanhem o futuro professor na sua trajetória profissional. Como diz Dias-da-Silva (2005), "não basta aos licenciandos participarem de projetos e vivenciarem o cotidiano escolar reduzido à perpetuação do senso comum. Sua formação intelectual é imprescindível!".

Dias-da-Silva (2005) argumenta que a profissionalização dos professores está diretamente ligada à trajetória dos cursos de licenciatura, responsáveis pela formação dos professores das séries iniciais ou das disciplinas específicas de $5^{a}$ a $8^{a}$ séries e ensino médio. A autora lembra que, historicamente, a cultura universitária "delegou reduzido prestígio à área de educação nos embates pela hegemonia acadêmica no campo da ciência brasileira".

Assim, para a autora, com a expansão do ensino fundamental e médio, a partir da década de setenta, as universidades brasileiras criaram, a seu modo, um modelo de formação de professores que atendesse à demanda crescente de estudantes nas escolas brasileiras. A chamada licenciatura curta era responsável pelos conteúdos que compunham a formação inicial dos professores.

Ainda para a autora, o modelo de três mais um, modelo de formação de professores para a educação básica, continua a perpetuar-se no país. A universidade tem valorizado, nas últimas décadas, um modelo de formação aligeirado e, ao mesmo tempo, desarticulado do processo de formação, pois tem permitido que os conteúdos de natureza pedagógica, mínimos exigidos pela legislação, sejam apresentados aos licenciandos no final do curso. É no último ano do curso de licenciatura que as disciplinas necessárias para a formação do professor são "ensinadas".

Para ela, os cursos de formação inicial têm valor significativo na vida profissional do futuro professor. Isso nos leva a considerar que tanto os professores quanto os gestores dos cursos de licenciatura podem ter um papel ativo na construção da profissionalidade dos futuros professores. Ao lado de outras iniciativas recentes que investigam a atuação do professor formador (ANDRÉ, 2006; MIZUKAMI, 2005), decidiu-se focalizar o trabalho dos chefes de departamento dos cursos de licenciatura. Quem são esses chefes? Como se deu sua formação e sua opção pelo magistério? Como percebem sua atuação como chefe? E como acham que os outros o vêem? Essas são algumas questões que orientaram nossa pesquisa.

\section{Processos de constituição identitária}

O conceito de identidade está vinculado ao processo de socialização, pois se considera a identidade como a constituição das características pessoais e sociais produzidas durante a trajetória de vida de um indivíduo. As situações

Rev. Diálogo Educ., Curitiba, v. 8, n. 23, p. 137-151, jan./abr. 2008 
Processos de constituição identitária dos chefes de departamento dos cursos de licenciatura

experimentadas ao longo da trajetória pessoal, por meio das relações sociais e das significações pessoais, constituem a identidade. Essas situações que permeiam as experiências pessoais constroem o "eu subjetivo" e, ao mesmo tempo, o intrapsicológico de uma pessoa. A identidade é o arcabouço pessoal, ou seja, é o reservatório de experiências que, aos poucos, o ser humano, por meio das relações sociais, estabelece para si por meio de e com o outro.

As concepções de identidade que fundamentam o presente estudo estão apoiadas nos escritos de Claude Dubar (2005), sociólogo francês que retoma a idéia de socialização tanto de Piaget, considerado pelo autor como um dos pioneiros nessa discussão, quanto de Durkheim. Ressalta-se que, para Dubar (2005), "a identidade nunca é dada, ela sempre é construída e deverá ser (re)construída em uma incerteza maior ou menor e mais ou menos duradoura".

Segundo esse autor, a identidade se constrói e reconstrói de acordo com as socializações estabelecidas ao longo da trajetória humana, nas interações sociais que são advindas das experiências familiares, escolares e do campo do trabalho. Já no nascimento, os pais conferem uma identidade aos filhos, pois reconhecem a criança tendo como referência particularidades do seu mundo vivido, originadas da própria experiência pessoal.

Vista sob esse prisma, a socialização é uma atividade de "pano de fundo" na constituição da identidade pessoal e profissional dos indivíduos. É por meio dos outros e nas relações sociais estabelecidas na trajetória individual, como ator e protagonista, ou seja, no espaço de interação e ação individual, que a identidade se constrói. Para Dubar (2005), esta é a identidade para si. No entanto, existe uma interlocução entre a "identidade para si" e a "identidade para o outro". É uma interlocução complementar e, ao mesmo tempo, problemática. Complementar porque não se pode "dizer" e/ ou se reconhecer sem ouvir o outro. Desse modo, o outro tem um papel fundamental na construção do "eu". O outro é como um espelho que, ao mostrar a imagem, contribui na constituição da identidade do indivíduo. É uma interlocução problemática, pois não se pode estar no lugar do outro; pode-se apenas ouvir o que o outro tem a dizer e, desse modo, refletir, acreditar e/ou ignorar aquilo que é dito.

\section{Procedimentos metodológicos}

A coleta de dados ocorreu no primeiro semestre de 2007, numa universidade privada do sul do país. Estão matriculados na universidade cerca de onze mil estudantes, distribuídos pelos 35 cursos de graduação, 03 programas de mestrado e o colégio de aplicação. É uma instituição com boa infra-estrutura, sendo que todas as salas de aulas são climatizadas e possuem projetor multimídia.

Rev. Diálogo Educ., Curitiba, v. 8, n. 23, p. 137-151, jan./abr. 2008 
Em 2007, a universidade matriculou 1279 alunos nos seus nove cursos de licenciatura: Matemática, Letras, Educação Física, História, Biologia, Geografia, Pedagogia, Artes Visuais e Ciências da Religião. Há 114 professores formadores para atender aos alunos da licenciatura.

Foram entrevistados os nove professores/chefes de departamentos dos cursos de licenciatura em dois momentos distintos. Inicialmente, para explicitar os objetivos da pesquisa e obter informações gerais sobre sua função. Em outro momento, foram coletados dados sobre a trajetória pessoal e profissional do professor-chefe de departamento, assim como sobre o cotidiano de seu trabalho na instituição.

No presente texto, serão discutidos dados que nos permitem conhecer melhor os processos de socialização profissional e as influências familiares, escolares e laborais na constituição identitária dos chefes de departamentos dos cursos de licenciatura.

\section{Influências na constituição da identidade profissional}

Nas entrevistas com os nove chefes de departamento, percebe-se, diante da história particular de cada um, diferenças na formação acadêmica e na trajetória profissional. Entre os chefes de departamentos, há filhos de agricultores, de professores, de colecionador de artes.

Cada chefe traz consigo as experiências da sua história familiar, escolar e dos demais processos de socialização. O cotidiano de trabalho, neste caso, é balizado pelas experiências sociais advindas da trajetória de vida.

Talvez, neste caso, a história de vida dimensione o habitus de cada um, aquilo que Dubar, apoiado nos estudos de Bourdieu, define com a "cultura do grupo de origem, incorporado à personalidade, importando seus esquemas a todas as situações ulteriores e provocando inadaptações cada vez que essas situações se afastam demais das situações da infância" (DUBAR, 2005).

As experiências vividas desde a infância acompanham as atividades profissionais e fazem com que os indivíduos recorram às experiências incorporadas quando se deparam com uma situação similar, ou seja, buscam em seu repertório cognitivo formas de enfrentar as novas situações.

\section{A formação acadêmica dos chefes de departamento}

Quanto à formação acadêmica, todos os chefes são graduados na área do curso em que exercem a chefia, assim como, dos nove, um é doutor, cinco são mestres e três são especialistas, um quadro esperado numa instituição privada. Uma razão apontada por um chefe de departamento para não fazer o mestrado é a dificuldade para conciliar horário na universidade e tempo para o deslocamento, já que na cidade não há mestrado na sua área.

Rev. Diálogo Educ., Curitiba, v. 8, n. 23, p. 137-151, jan./abr. 2008 
Processos de constituição identitária dos chefes de departamento dos cursos de licenciatura

\section{Tempo de exercício na docência}

Quanto aos anos de experiência no magistério, os chefes de departamento estão assim distribuídos:

Menos de 20 anos $=2$ chefes de departamento: um com 13 e outro com 16 anos de experiência.

De 21 a 30 anos $=3$ chefes de departamento: um com 21, um com 22 e outro com 26 anos de experiência.

De 31 a 40 anos $=4$ chefes de departamento: dois com 34, um com 35 e um com 38 anos de experiência.

Dados obtidos por meio das entrevistas com os nove chefes de departamento.

Esse quadro mostra que todos têm uma longa experiência docente. Sete chefes de departamento estão aposentados e continuam trabalhando na instituição. No decorrer da pesquisa, procurar-se-á explorar melhor os motivos que levam esses docentes a permanecer por tão longo tempo na instituição.

\section{Os modelos na constituição da identidade profissional}

Uma questão importante revelada pelos chefes de departamento referese aos modelos profissionais. Ex-professores da educação básica e familiares professores são os responsáveis pelas escolhas profissionais de alguns deles. A admiração diante da didática de um professor, ou mesmo do vínculo que se estabeleceu na relação entre professor e estudante, filhos e pais, podem incitar o desejo de repetir tal modelo profissional, neste caso, na docência. Um exemplo pode ser observado na fala de um chefe de departamento para quem a escolha profissional foi...

Bem fácil... Desde menina brincava de escolinha, na escola arrumava todos os erros de português, de gramática, situação, de todos os colegas que me circundavam, então já sabia que queria ser professora. No ensino médio chegou na hora de resolver: vou fazer magistério.

[...] detalhe meu pai é professor, meu avô é professor, minha mãe é professora, minha irmã é professora, todos

Rev. Diálogo Educ., Curitiba, v. 8, n. 23, p. 137-151, jan./abr. 2008 
os meus irmãos já deram ou dão aula, então tem isso na família. Meu pai como professor sempre foi modelo assim não só como pai, quando eu não sabia alguma coisa que a professora explicava na escola de qualquer matéria, se eu não entendia chegava em casa e dizia: pai como que é isso? $\mathrm{Na}$ mesa, na hora do almoço, na frente de todo mundo ele explicava e sempre explicava de um jeito muito simples, então eu achava que era assim que eu queria ser. $\mathrm{Na}$ escola eu tive excelentes professores, um professor de matemática que tinha uma didática impecável, no uso do quadro-de-giz, então eu me inspirava naquilo que eu gostava em cada professor e aquilo eu procuro fazer (Rita).

\section{O papel do outro na construção da auto-imagem do chefe de departamento}

Por meio da interação humana, o indivíduo é reconhecido, avaliado e conceituado pelo outro. A relação interpessoal possibilita a construção de esquemas mentais que reconhecem as atitudes, os valores e os modos de fazer das pessoas que nos circundam.

Segundo Dubar (2005, p. 25):

A identidade humana não é dada, de uma vez por todas, no nascimento: ela é construída na infância e, a partir de então, deve ser reconstruída no decorrer da vida. O indivíduo jamais a constrói sozinho: ele depende tanto dos juízos dos outros quanto de suas próprias orientações e autodefinições. A identidade é produto de sucessivas socializações.

A identidade, vista sob este aspecto, é afetada e construída por meio dos juízos dos outros. São estas avaliações e definições dos outros para o indivíduo, e por meio das ponderações que este realiza sobre si, que a identidade é construída e reconstruída. Naturalmente que a imagem que o indivíduo acha que os outros têm de si contribui na construção da auto-imagem. Desse modo, o indivíduo se constrói com e por meio do outro, nas relações sociais que estabelece.

Cada chefe de departamento tem uma auto-imagem por meio do outro e falar sobre esta auto-imagem foi algo interessante e intrigante, pois se observou a dificuldade que alguns chefes tiveram para falar sobre si. Enxergar-se de fora para dentro não parece ter sido uma ação simples. Cada chefe de departamento parou para pensar e para tentar se avaliar por meio dos olhos do outro.

Às vezes, parece que o acúmulo de tarefas do chefe de departamento impede ou dificulta enxergar o outro, como expressa a professora Rita:

Rev. Diálogo Educ., Curitiba, v. 8, n. 23, p. 137-151, jan./abr. 2008 
Processos de constituição identitária dos chefes de departamento dos cursos de licenciatura

Eu acho que todo mundo me vê como uma pessoa muito exigente. Por dois motivos: porque geralmente no corredor eu não ando sorrindo, não sou uma pessoa assim sempre sorridente, estou sempre pensando nas coisas que eu tenho que fazer. Às vezes não cumprimento um aluno que passou, eu acho que está errado!

O tempo acelerado e escasso se apossa dos pensamentos e dos movimentos da professora. Caminhar pelos corredores da universidade passou a ser uma extensão da agenda e de seus compromissos individuais. O outro se torna invisível diante de tantos afazeres.

Situações como estas inibem a aproximação do estudante à pessoa do chefe de departamento. "Então são muitas preocupações e, às vezes, eu até passo por antipática e aqueles que não foram meus alunos, dificilmente vêm me pedir alguma coisa, ou pedem por meio de outro ou vão até a secretária do departamento, ou nem vêm, tem medo de mim! Dizem que eu tenho um olhar assim..." (Rita).

Somente quem a conhece em um espaço diferenciado, como o da sala de aula, momento que assume o papel de professora, na proximidade com os estudantes, é que a imagem dos outros sobre si se altera. "Quem tem aula comigo sempre diz que a professora é exigente. Mas quem já teve aula sabe que esse exigente não é bem assim, ela é maleável" (Rita). Seu depoimento revela percepções diferentes segundo o papel desempenhado: como chefe sente-se mais distante do que como docente.

Um outro chefe de departamento faz uma leitura muito positiva de si mesmo pelo olhar do outro:

Acho que como, pelo menos dito por alguns dos alunos, eles me vêem como a pessoa que está próxima deles, acessível, aberta a ouvir, que podem contar comigo, inclusive os próprios colegas, penso que também não é muito diferente, porque até quando você coloca, ele diz: você conduz bem porque você tem paciência, você ouve, porque você isso, porque aquilo, então eles acabam dizendo: não, você conduz bem, você pondera. [...] eu acho que é desta forma mesmo que eles me reconhecem como uma pessoa que tem equilíbrio e que eles podem contar e que também sou um deles, que eu estou aqui, simplesmente, com uma responsabilidade a mais do que eles (Pedro).

Pedro se vê muito próximo de seus pares e alunos, não deixa de lado que é um professor, e que, momentaneamente, está em uma condição diferenciada, com uma responsabilidade a mais do que os professores formadores.

Rev. Diálogo Educ., Curitiba, v. 8, n. 23, p. 137-151, jan./abr. 2008 
Destaca-se como uma pessoa equilíbrada, que consegue ser ponderado, paciente e que é capaz de ouvir o outro. Esses são fatores essenciais no relacionamento humano e, pela auto-imagem que tem de si, por meio da fala do outro, parece satisfeito consigo e com sua forma de atuação.

Para um outro chefe de departamento, a lembrança do seu nome pelos colegas nos momentos que antecedem a eleição é a demonstração da confiança que sentem em seu trabalho. "[...] O meu nome sempre é lembrado para ser chefe. Que nem eu fui chefe algum tempo atrás, depois foi outra pessoa, daí chegou uma hora que foi unânime, e agora é você, enfim, eu penso que sou bem aceito" (Carlos). Isso demonstra que a aceitação pelos colegas professores do departamento é muito importante para a construção da auto-imagem:

[...] Às vezes a gente ouve elogios, assim, mas é. No departamento praticamente não tem essa cultura de rasgar ceda, vamos dizer assim, mas o que eu ouço, às vezes, que as pessoas falam é que particularmente eu tenho uma boa capacidade de síntese e tenho geralmente visão do todo e consigo ser objetivo nas minhas expressões e, isso, gera confiança (Carlos).

Objetividade e clareza na comunicação são qualidades apontadas como importantes para os integrantes deste departamento, segundo a menção do chefe. Talvez por ser um departamento envolvido diretamente com a lógica, este fator seja importante no processo comunicativo. Boa capacidade de síntese e visão do todo gera confiança, segundo sua fala. É interessante perceber estes aspectos como fatores geradores de confiança. Parece que isso demonstra que o chefe representa a maneira deles, ou seja, a clareza e objetividade fazem parte de um departamento que lida com o desenvolvimento de raciocínio lógico.

Valorização e aplicação das normas para a resolução de muitas questões do departamento são apontadas por um outro chefe de departamento como muito importantes. Ele ressalta que a imagem que os outros tem de si é de uma pessoa metódica.

Eu imagino que eles me vêem, eu percebo assim que, a impressão que eu tenho é de que eles me acham uma pessoa metódica, dada questão de encaminhamento burocrático, sinto que essa é uma impressão, talvez a questão de ser um pouco enérgica, passa tanto para os alunos quanto para os colegas [...] (Tania).

A atitude metódica pode ser confundida com o cumprimento burocrático e isso causa uma imagem não muito positiva, segundo esse chefe de departamento:

[...] Acho que eles têm essa impressão que eu talvez seja firme, não sei se demais ou não, mas eu penso isso, o que mais? Talvez essa questão de ser enérgica, a questão de

Rev. Diálogo Educ., Curitiba, v. 8, n. 23, p. 137-151, jan./abr. 2008 
Processos de constituição identitária dos chefes de departamento dos cursos de licenciatura

colocar regras, de tentar me pautar por elas, eu sinto que nem sempre isso é visto pelo lado positivo, eu acho que tem os dois lados fica bem uma dicotomia, uns entendem isso como sendo positivo e outros entendem isso como negativo (Tania).

Além de se ver sob os olhos dos colegas, o chefe de departamento também considera que essa função compromete a relação com seus alunos, que confundem os papéis de professor e de chefe:

Os meus alunos, aqueles com quem eu estou em sala, eu percebo que muitas vezes eles confundem, eles se sentem constrangidos em conversar comigo como professora, às vezes eu percebo que até algumas questões da classe, da disciplina, de algumas coisas assim, eles até gostariam de estar colocando alguma outra coisa e, às vezes, não o fazem porque vêem em mim a chefe, eu vejo que mistura, por mais que eu procure colocar assim, mas eu vejo que, em alguns momentos, a coisa mistura. Eles me procuram quando querem tratar de outras coisas, mas, a questão da própria disciplina, do encaminhamento da disciplina eu tenho que provocar situações, mais de uma vez, para que a coisa aconteça, acaba acontecendo, mas eu vejo que tem certa resistência (Tania).

Os alunos não se sentem à vontade para conversar com o professor, que também é chefe de departamento. Será que é o papel de chefe de departamento que não se desprende do professor, quando está em sala de aula? Ou será que o chefe não consegue se desvencilhar da função quando está em sala de aula? Será que a atividade metódica engessa a pessoa do chefe?

Para um chefe de departamento, as palavras "ouvidora" e "costureira" constituem a auto-imagem que tem de si. Por meio da procura do outro para conversar e resolver as questões pessoais, ela acredita que tem desenvolvido bem a sua função. "Pela procura deste cantinho para conversar, eu acho que aquele ouvido que eu disse que eu tinha, me parece que eu tenho, me parece que não é uma ilusão minha, eu acho que eu sou uma boa ouvidora, acho que sou uma boa costureira" (Vanessa). Ouvir e costurar os fatos e acontecimentos apresentados a ela faz com que a chefe de departamento acredite na resolução de muitos dos conflitos interpessoais e, mesmo pessoais, que ocorrem entre os integrantes do seu departamento. Parece que para ela os problemas que surgem nas relações humanas são passíveis de consertos.

Não deixa de ser verdade que o chefe de departamento precisa estar preparado para resolver, da melhor forma possível, os conflitos que ocorrem. A disponibilidade para ouvir, analisar e orientar os indivíduos diante de algum conflito pessoal ou interpessoal é uma das responsabilidades do chefe de departamento, conforme apontado por eles.

Rev. Diálogo Educ., Curitiba, v. 8, n. 23, p. 137-151, jan./abr. 2008 
O chefe de departamento que está há trinta e seis anos na instituição se sente muito realizado ao término do seu mandato. Diz que não se candidatará mais para a função na próxima eleição, pois já contribuiu o suficiente com seu departamento. Em sua trajetória, cumpriu alguns mandatos como chefe ou vicechefe e afirma que tanto professores quanto alunos têm uma imagem muito positiva de sua pessoa. Esclarece que os adjetivos positivos que ouve sobre si se dão em virtude da maturidade e experiência adquirida ao longo da trajetória universitária.

Já um outro chefe de departamento afirma que "eles têm segurança por eu ter atuado tanto tempo na área. [...] Eu acho que sou bastante aberta para o diálogo, procuro não ser uma pessoa difícil nas relações" (Vera).

Um outro chefe de departamento pensa "que uma das características da função é a questão da democracia mesmo, conseguir ouvir as pessoas, tentar chegar a um consenso, e também do senso de compromisso, a gente está sempre aqui disposto a ouvir e a tentar resolver os problemas" (Lucia). Mostra um pouco de dificuldade para iniciar a fala a respeito de como acha que os outros a vêem como chefe de departamento:

\footnotetext{
É difícil colocar como os outros vêem a gente, mas penso que esta questão da democracia e de também oportunizar alguns professores o acesso, estimular alguns professores que a gente vê que estão lá mais quietinhos e trazer, fazer agregar, somar com o grupo, não só um ou outro, mas, sempre se destacando, porque todos têm alguma coisa a contribuir, e minha contribuição foi nesse sentido de agregar o grupo e tentar valorizar alguns valores que passam meio despercebidos (Lucia).
}

Parece que ela não conseguiu se imaginar por meio do outro. Como ela mesma disse, se enxergar por meio do outro não é um exercício fácil. Fixou-se mais na sua experiência e nas suas atitudes como chefe de departamento, nas suas iniciativas e nas contribuições para com os outros enquanto chefe de departamento.

Um outro chefe de departamento diz que dos "alunos eu não sinto nenhuma restrição. No primeiro ano foi difícil. O primeiro ano tinha muita coisa por fazer, tinha uma angústia dos alunos, porque o chefe de departamento antigo tinha ficado muito tempo também, então tinha toda uma estrutura que já era de outro jeito" (Alberto). Esta fala demonstra o tempo que o chefe de departamento necessita para inserir o seu modelo de trabalho e se adaptar às pessoas e aos procedimentos existentes na universidade. Realmente deve ser difícil dormir professor e acordar gestor. É um trabalho de mudança de olhar, novos afazeres que exigem novas aprendizagens, novas competências.

Rev. Diálogo Educ., Curitiba, v. 8, n. 23, p. 137-151, jan./abr. 2008 
Processos de constituição identitária dos chefes de departamento dos cursos de licenciatura

Os alunos parecem esperar grandes mudanças quando há troca de chefe de departamento e que as melhorias sejam realizadas de imediato. Isso é o que um dos chefes percebe:

Não sei se eles esperavam muita mudança e foi complicado, mas hoje eu vejo que tenho bastante aceitação, a gente de vez em quanto pisa na bola, os alunos vem e reclamam, mas nós temos um relacionamento super bom, não vejo problemas (Alberto).

As análises mostram relatos profundos e, em alguns momentos, relatos de sofrimento. Enxergar-se por meio dos olhos do outro trouxe, para alguns chefes, o sentimento de insegurança, de medo. É uma descoberta, ou melhor, um desvelamento, é uma oportunidade de perceber-se. Ao término de uma entrevista, um chefe de departamento disse: "Puxa, foi bacana, parar e falar um pouco sobre mim. Foi bacana me avaliar um pouco. $\mathrm{Na}$ correria do dia-a-dia não tenho tempo para fazer isso. Durante a entrevista pude perceber as questões que preciso melhorar. Foi muito bom me ouvir" (Vanessa).

\section{Em síntese}

O trabalho dos chefes de departamento é marcado pelo excesso de atividades, muitas delas burocráticas. Em alguns relatos, as falas dos chefes indicam um sentimento de frustração por não conseguir atender a todas as demandas da universidade. O trabalho mais desafiador, segundo eles, é o acompanhamento do orçamento e a confecção das planilhas de custos e orçamento. O controle financeiro das receitas e despesas do departamento é uma das atividades que requer um tipo de conhecimento não aprendido pela maioria dos professores que se tornam chefes de departamento.

Assim como as questões que envolvem o orçamento, pode-se dizer que as análises das campanhas de marketing e a preocupação com o fechamento do número de inscrições para o vestibular também são situações diferentes das preocupações com a docência. Esta é uma responsabilidade que, aos poucos, está sendo depositada nos ombros dos chefes de departamento.

A universidade tem se utilizado de uma forma "democrática" e "transparente" de, nas reuniões administrativas, mostrar os resultados financeiros por departamento. Esta prática, que não é de todo negativa, tem causado, porém, um mal-estar para os chefes que não conseguem atingir as metas estabelecidas no orçamento. Essa é considerada uma forma de gestão co-participativa e co-responsabilizada, pois os integrantes dos departamentos são, também, co-responsáveis pelo alcance - ou não - dos resultados.

Rev. Diálogo Educ., Curitiba, v. 8, n. 23, p. 137-151, jan./abr. 2008 
Esta é uma prática ligada ao modelo neoliberal que, aos poucos, está sendo transplantado para a universidade. Como diz Pérez Gómez (2001, p. 151):

Como a intensa competitividade internacional está exigindo das empresas extremar a eficiência de seus procedimentos, de suas tarefas, estruturas organizativas e interações pessoais, para alcançar e oferecer no mercado o produto mais competitivo, ou seja, o máximo de aceitação ao mínimo custo, também das escolas deve-se exigir similar esforço e competência na elaboração eficaz de seus procedimentos, de suas estruturas organizativas e interações pessoais para produzir rendimentos acadêmicos ao menor custo.

Outro fator que vale aqui destacar é a confusão de papéis que os próprios chefes e estudantes fazem entre a docência e a chefia. Em alguns momentos e, para alguns chefes, a separação entre uma e outra não é tarefa fácil. Há um incômodo por parte de alguns chefes quanto a essa questão. Será que deveriam atuar somente como chefes, o que lhes daria mais tempo para atender as demandas da universidade? Mas isso não os afastaria cada vez mais de seu papel pedagógico?

O chefe de departamento é muito requisitado, segundo seus depoimentos, para resolver conflitos entre os professores e estudantes, assim como entre os próprios estudantes. O papel de orientador educacional e/ou psicólogo também é exercido por ele. Em uma das entrevistas presenciamos a chegada de uma estudante aos prantos, que queria falar com o chefe de departamento. Era uma questão pessoal que a levou a pedir ajuda para o chefe. Inferimos que este tipo de situação deva ser comum, pois, segundo alguns chefes, o ingresso de universitários cada vez mais jovens tem gerado certos problemas, próprios do final da adolescência. A disponibilidade para ouvir e orientar requer paciência, tempo, preparo dos chefes de departamento. Será que estão preparados?

Outra questão relevante é o tempo necessário para os chefes se adaptarem à função, ou seja, o tempo necessário para o aprendizado das tarefas. Apesar de encontrar suporte para sanar as dúvidas nos diversos departamentos da universidade, tais como: financeiro, marketing, pró-reitoria de ensino, compras, secretaria, os chefes dizem que o tempo para aprender os procedimentos para realizar as suas atividades é relativamente longo. É uma fase de aprendizado angustiante para alguns chefes.

A análise dos aspectos pessoais dos chefes de departamento culmina na forma específica de como cada um administra seus afazeres e seu equilibrio emocional. Esta dimensão pessoal está diretamente vinculada às diretrizes institucionais. É aquilo que Pérez Gómez (2001) diz: “o desenvolvimento

Rev. Diálogo Educ., Curitiba, v. 8, n. 23, p. 137-151, jan./abr. 2008 
Processos de constituição identitária dos chefes de departamento dos cursos de licenciatura

institucional se encontra intimamente ligado ao desenvolvimento humano e profissional das pessoas que vivem a instituição e vice-versa; a evolução pessoal e profissional provoca o desenvolvimento institucional".

Considerar, desta forma, as tensões, as angústias, as satisfações expressas pelos professores que estão atuando como chefes de departamento pode ser muito útil para fazer as mudanças necessárias a uma gestão que promova o desenvolvimento humano e profissional das pessoas que vivem a instituição. Esse esforço beneficiará tanto os gestores quanto todo o processo de formação, pelo qual a instituição responde, pois como diz Pérez Gómez, a evolução pessoal e profissional provoca o desenvolvimento institucional.

\section{REFERÊNCIAS}

ANDRÉ, M. E. D. A et al. Pesquisas sobre formação de professores: uma análise das racionalidades. Educação \& Linguagem, São Paulo, Ano 9, n. 14, p. 90-104, jul./dez. 2006

DIAS-DA-SILVA, Maria Helena G. Frem. Políticas de formação de professores no Brasil: as ciladas da reestruturação das licenciaturas. Perspectiva: Revista do Centro de Ciências da Educação, Florianópolis, v. 23, n. 2, p. 381-406, jul./dez. 2005.

DUBAR, Claude. A socialização: construção das identidades sociais e profisisonais. Tradução de Andréa Stahel M. da Silva. São Paulo: Martins Fontes, 2005.

IMBERNÓN, F. Formação docente e profissional: formar-se para a mudança e a incerteza. São Paulo: Cortez, 2004.

MIZUKAMI, Maria da Graça N. Aprendizagem da docência: professores formadores. In: RAMANONSKI, J. P.; MARTINS, P. L. O.; JUNQUEIRA, S. R. A. J. (Org.). Conhecimento social e conhecimento universal: aulas, saberes e políticas. Curitiba: Champagnat, 2005. p. 69-80. v. 5.

PÉREZ GÓMEZ, A. I. A cultura escolar na sociedade neoliberal. Tradução de Ermani Rosa. Porto Alegre: ARTMED, 2001.

Recebido: 15/10/2007

Received: $10 / 15 / 2007$

Aprovado: 05/11/2007

Approved: 11/05/2007

Rev. Diálogo Educ., Curitiba, v. 8, n. 23, p. 137-151, jan./abr. 2008 